\title{
Antimicrobial Activity of Lysozyme Against Oral Pathogens
}

\author{
T. Jesse Joel*, S. Suguna S and S. R. Steffi \\ Department of Biotechnology, School of Biotechnology \& Health Sciences, \\ Karunya University, Coimbatore-641 114,Tamil Nadu, India; jessejoel@karunya.edu
}

\begin{abstract}
Saliva contains a number of antimicrobial substances which have their origin either in salivary glands or serum from which they may leak into the mouth via the gingival crevices. Saliva is believed to possess a substantial influence on the aggregates oral pathogens form in the mouth due to the antibodies as well as proteins whose antimicrobial properties do not depend on prior exposure to an antigen. One such enzyme is Lysozyme which is one of the most powerful natural antibacterial and antiviral compounds known to man. According to previous researches, it has been found out that lysozyme may bind and aggregate Gram-positive bacteria such as putative Gram-negative periodontopathic bacteria such as Capnocytophaga gingivalis. This particular study explores the natural phenomenon Lysozyme exhibits against oral microflora with noteworthy conclusions. Saliva samples were collected from the oral cavity of human, cow and dog. From these samples, lysozyme was isolated and purified. Furthermore, the quantity of the enzyme isolated was ascertained by Polyacrylamide Gel Electrophoresis. The quantified enzyme showed 32kDa for cow sample, 23kDa for dog sample and $23 \mathrm{kDa}$ for human sample. Finally the antimicrobial activity of the enzyme was determined by agar well diffusion method against Staphylococcus spp. and Enterococcus faecalis. Hence lysozyme in saliva is found to have the antibacterial activity against the pathogen due to the zone of inhibition observed and this proves that a tool to prevent dental decay is available and that there is potential to serve antimicrobial role in the specific application of medical industry.
\end{abstract}

Keywords: Lysozyme, Oral Microflora, Saliva, Decay, Antibacterial Activity

\section{Introduction}

Saliva is an essential fluid for the health of human teeth and mucosal surface. The basic protective mechanism mediated by saliva is bacterial but saliva contains also a number of antimicrobial substances which have their origin either in salivary glands or serum from which they may leak into the mouth via gingival crevices scattered aggregation of lymphoid tissue at various sites in the human mouth and also produce protective agents. Both the salivary glands contain antibodies as well as proteins whose antimicrobial properties do not depend upon prior exposure to an antigen non-immunoglobulin defense factor .many of these factors are common to most human external secretions e.g., milk, tears and saliva share a very similar pattern of antimicrobial agents. Especially lysozyme, lactroferrin and peroxidise enzyme are found in substantial concentration in all secretions. ${ }^{1}$ Lysozymes, also known as mermaids, are compounds that help break the complex chemical bonds by hydrolysis. These biocatalysts hydrolyze the NAM and NAG residues in the cell wall of Chitodextrins. Body discharges like tears, saliva, human milk, and mucus have good amounts of the enzyme and Lysozyme is also predominant in egg white, macrophages and Poly nuclear neutrophils. Lysozyme activity may result from activation of endogenous bacterial lytic enzyme(s) by the lysozyme-chloride complex. The enzyme has been reported in the past thirty years to act very effectively against bacteria and viruses thereby increasing the shelf-life of food products and helps avoid

${ }^{*}$ Author for correspondence 
spoilage and accomplishes food safety. Due to this fact, Lysozyme is known to increase immunity and therefore is reported to be used in pediatric foods and in patients suffering from gastro problems. Lysozyme has been widely used for over 50 years as an "endogenous antibiotic" in the pharmaceutical industry. It treats and prevents a variety of conditions, particularly viral and bacterial infections, and is especially effective as a prescription drug for use in the treatment of viral forms, localized or systemic inflammatory processes and gastrointestinal disturbances, mostly in formula fed infants. This important biocatalyst has been used as a marker in various infections in humans. It is also used as an indicator of health and infection in animals and humans, for patients with ulcers, erysipelas and microbial eczema. This $14-\mathrm{kDa}$ basic protein lyse the outer wall of bacteria by destroying the 1,4 glycoside linkages between $\mathrm{N}$-acetylmuramic acid and $\mathrm{N}$ acetyl glucosamine of the peptidoglycan. Members of the normal oral flora have been found to be relatively insensitive to lysis by lysozyme ${ }^{2}$. However, lysozyme may bind to aggregate Gram-positive bacteria such as Streptococcus mutans, other streptococci and putative Gram-negative periodontopathic bacteria such as Capnocytophaga gingivalis. Binding is thought to involve cationic portions of the molecule interacting with anionic bacterial surface components, as well as specific recognition of bacterial cell wall sugars by the enzyme-active site. The addition of sodium chloride to aggregated bacteria insensitive to muramidase activity leads to cell lysis, perhaps by the activation of endogenous bacterial lytic enzyme(s) by the lysozyme-chloride complex. Lysozyme is also known to inhibit glucose fermentation by oral streptococci ${ }^{3-5}$. Dental plaque is consider to be one of the major disease which is caused by multidrug resistant bacteria and the saliva of the animals finds the solution to it by inhibiting those bacteria. The saliva of the cow, dogs, human contains lysozyme which are very effective and responsible for the inhibition of the bacteria and hence it is considered to prevent dental plaque ${ }^{6}$. Thus the efficiency of the anti-bacterial properties of Lysozyme in all three samples is determined through this study.

\section{Materials and Methods}

\subsection{Collection of Sample}

A total of $25 \mathrm{ml}$ of saliva was collected from the oral cavity of human, cow and dog using sterile buds and was collected in a sterile test tube with $5 \mathrm{ml}$ of saline $(0.02 \mathrm{gm}$ of $\mathrm{NAOH}$ in $10 \mathrm{ml}$ of distilled water $)^{4}$. Then the sample was stored in a refrigerator.

\subsection{Isolation and Purification of Lysozyme}

The saliva was then centrifuged for 5 minutes at $4^{\circ} \mathrm{C}$ at $10,000 \mathrm{rpm}$. The supernatant was collected and to it $0.2 \%$ of sodium azide was added and was stored at $4^{\circ} \mathrm{C}$. Cautiously and aseptically prepared $50 \% \mathrm{ml}$ of Polyethylene Glycol (PEG) and $30 \%$ of sodium sulfate were added to the above supernatant and stabilized at a $\mathrm{pH}$ of 9.0. After that the sample was incubated for $1 \mathrm{hr}$ and centrifuged at 10,000 $\mathrm{rpm}$ for $20 \mathrm{~min}$. The formed fractions were dialyzed separately against Phosphate Buffer Saline (PBS) pH 7 and then analyzed for the concentration and lysozyme activity ${ }^{7}$.

\subsection{Quantification of the Enzyme}

Using $15 \%$ of SDS-PAGE and recommended stain (Coomasie Blue) the molecular weight was determined using standard procedure.

\subsection{Reagents for Antimicrobial Activity Disc Diffusion Method}

About 38.0 grams of Muller Hinton agar medium and 5.0 grams of Agar-Agar was suspended in $1000 \mathrm{ml}$ of distilled water and the prepared medium was autoclaved at $15 \mathrm{lbs}$ pressure $121^{\circ} \mathrm{C}$ for 15 minutes.

\subsection{Preparation of Agar Plates for Antimicrobial Activity}

For antibacterial activity, freshly prepared Muller Hinton agar was poured into a petri plate depth of about $4 \mathrm{~mm}$. The agar medium was allowed to cool to room temperature and stored at $4^{\circ} \mathrm{C}$.

\subsection{Inoculum Preparation}

The isolates of bacterial culture are used as strains. A loop of single colony of each test strain was grown overnight containing Brain Heart Infusion medium on a shaker (150 rpm) at $35^{\circ} \mathrm{C}$.

\subsection{Inoculation of Test Plate}

Sterilized cotton swab was introduced into the bacterial inoculum so that culture is absorbed onto the swab. The swab with culture is then used to make a lawn culture 
over the entire agar surface in a petri dish so that an even distribution of inoculum is obtained.

\subsection{Protein Separation by SDS-PAGE}

Sodium Dodecyl Sulphate (SDS) is an anionic detergent which denatures proteins by enveloping the polypeptide central supporting chain, SDS binds to proteins and deliberates a negative charge to the polypeptide so that a cloud with equal charge or charge is formed. The disulphide bridge are reduced by dithiothreitol. The polymer complex when formed turns into gel and by using electricity the proteins are pulled through the gel, the entire process is called Polyacrylamide Gel Electrophoresis (PAGE). The electrophoresis proteins can be suitably be seen by the stain like Coomassie blue or silver nitrate etc. (Figure 1).

\subsection{Gel Casting}

1. The cleaned glass plates with given spacers is arranged.

2. Preparation of Separating/lower gel:

$\begin{array}{ll}30 \% \text { Acrylamide } & 5.5 \mathrm{ml} \\ 1.5 \mathrm{M} \text { Tris }(\mathrm{pH} 8.8) & 3.75 \mathrm{ml} \\ 10 \% \text { SDS } & 150 \mu \mathrm{l} \\ \text { Double Distilled Water } & 6 \mathrm{ml}\end{array}$

3. The filter is mixed and subjected to vacuum for $5 \mathrm{~min}$.

4. Catalyst:

$\begin{array}{ll}10 \% \text { APS } & 150 \mu \mathrm{l} \\ \text { TEMED } & 13 \mu \mathrm{l}\end{array}$

5. Mix the solution quickly and avoid bubble formation.

6. Dispense the prepared gel in between the glass plates and allowing enough space for Stacking gel. Cover the separating gel so that no atmospheric air comes into contact.

7. Let the setup be undisturbed for 45-50 mins.
8. Remove unnecessarily accumulated water.

\subsection{Stacking or Upper Gel}

1. Similarly, The gel is prepared as follows:

$\begin{array}{ll}\text { Dist. Water } & 1700 \mu \mathrm{l} \\ 30 \% \text { Acrylamide } & 410 \mu \mathrm{l} \\ \text { 0.5M Tris (pH6.8) } & 310 \mu \mathrm{l} \\ \text { Double Distilled Water } & 25 \mu \mathrm{l}\end{array}$

2. Subjected to vacuum for $5 \mathrm{~min}$ and add the TEMED and APS as follows.

$\begin{array}{ll}10 \% \text { APS } & 25 \mu \mathrm{l} \\ \text { TEMED } & 2.5 \mu \mathrm{l}\end{array}$

3. Mix the solution quickly and avoid bubble formation and dispense the solution between the glass plates above the separating gel.

4. Using the Teflon Comb insert it carefully to avoid bubbles and leave the setup undisturbed for 45-60 minutes to let the stacking gel form a complex.

5. Remove the comb cautiously and flush the wells to wash using a needle.

\section{Results and Discussion}

\subsection{Estimation of Total Protein}

Overall protein content in saliva as well as the isolated lysozyme was estimated by measurement of the absorbance at $280 \mathrm{~nm}$ in UV-Vis spectrophotometer. And the absorbance of the samples was found to be human $(0.419 \mathrm{~nm})$, cow $(0.314 \mathrm{~nm})$ and $\operatorname{dog}(0.292 \mathrm{~nm})$.

Protein was separated using SDS-PAGE and is possibly the globally accepted method.

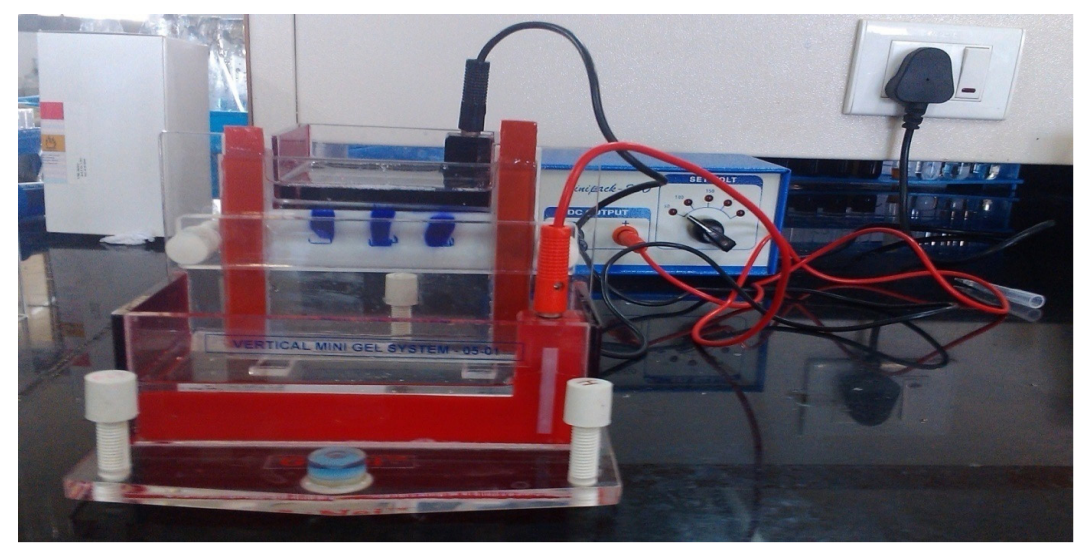

Figure 1. Sodium Dodecyl Sulphate - Poly Acrylamide Gel Electrophoresis (SDS-PAGE) Apparatus setup. 
The protein is therefore quantified. Further, the analysis proved to be quite noteworthy as the values were found to be $32 \mathrm{KDa}$ for Cow sample, $23 \mathrm{KDa}$ for Dog sample and $23 \mathrm{KDa}$ for Human sample, interestingly similar to that of a Dog.

\subsection{Antimicrobial Activity}

Four wells are made in each of the Petri plates that were swabbed with bacteria. Different concentrations $(25 \mu \mathrm{l}$, $50 \mu \mathrm{l}, 75 \mu \mathrm{l}, 100 \mu \mathrm{l})$ of the Lysozyme are added in three wells respectively. Similarly done with the saliva of human, cow and dog.

The inoculated plates were incubated for $24 \mathrm{hrs}$ and it was observed that various zones of inhibition were obtained. These zones were uniformly circular. The diameter of the zones was not of importance but the formation. The zones were conspicuous and therefore noteworthy.

\section{Conclusion}

Many antimicrobial agents are understood to possess bacteriostatic or bactericidal effects on mutants. Very little proof exists to show that they also affect oral cariogenic flora invivo. Recent studies have shown that some salivary systems can act synergistically against Streptococcus mutans the principle etiology of Dental caries. Such synergy is likely to be present in the oral cavity. Earlier studies have attempted to study proteins such as peroxidase, lactoferrin, and the enzyme used in the present study, lysozyme to oral health products ${ }^{5-9}$. Although clinical evidence is still limited, the concocted idea that such antimicrobial agents can be used as "natural antibiotics",

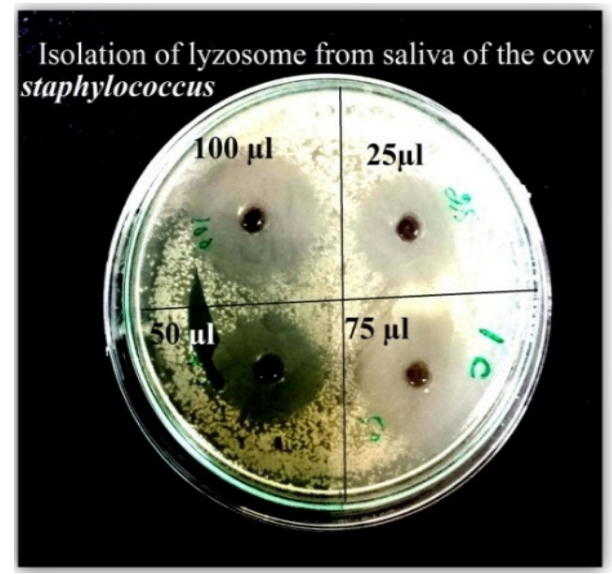

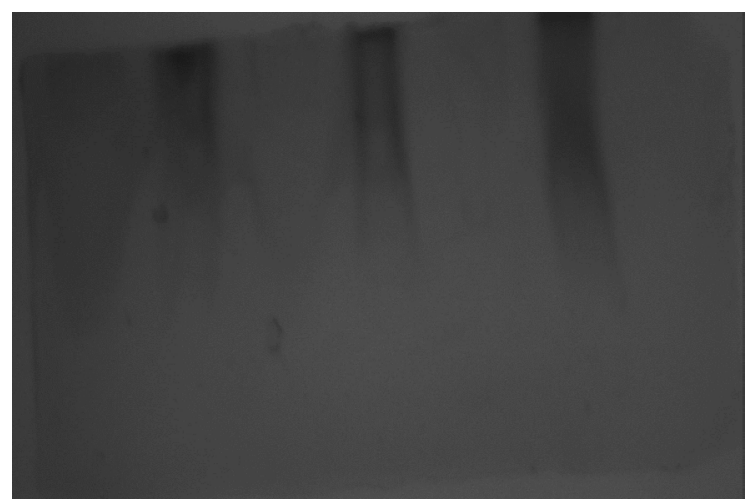

Figure 2. SDS TRIAL RUN.

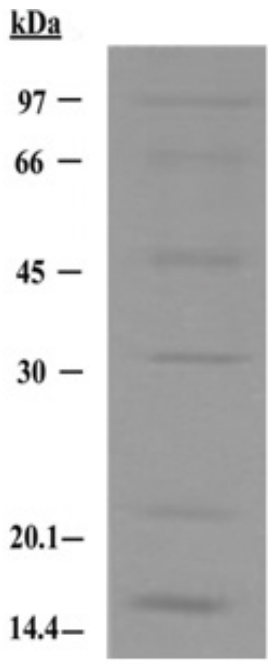

(a)

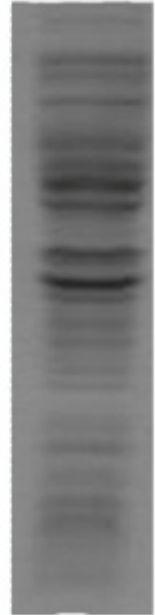

(b)

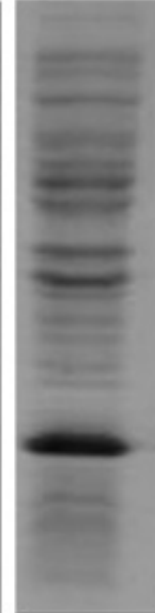

(c)

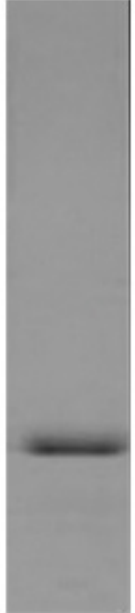

(d)
Figure 3. Results of SDS PAGE. (a) Control (b) Cow sample (c) Dog sample (d) Human.

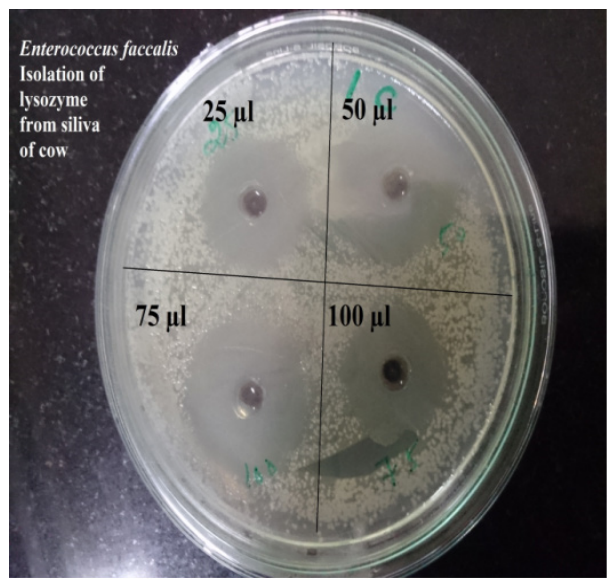

Figure 4. Zone of inhibition due to Antimicrobial activity observed by Lysozyme on microorganisms Staphylococcus sps. and Enterococcus foecalis. 
as an alternatives to health detrimental synthetic agents against cariogenic bacteria seems a promising research prospect. The mammalian body have been blessed with ultimate innate defense factors in saliva such as Lysozyme and Lactoferrin, these contribute hugely to mucosal security and control certain microbial populations in the oral cavity, especially Candida $s p p \cdot .^{10-12}$. On the other hand, Histatins are important constituents of the salivary proteins which possess substantial defence mechanisms for patients with salivary dysfunction. It is seen that Saliva exhibits multiple host defense functions such as homeostatic processes, lubrication, antimicrobial activity and the control of demineralization of teeth. Hence, lysozyme in saliva is found to have the antibacterial activity against the pathogen since it shows the zone of inhibition and it is proved to prevent the dental plaque. We believe that the work presented in this study suggests that lysozyme has the potential to serve such a role in the specific application of medical industry.

\section{References}

1. Tenovo J. Clinical applications of antimicrobial host proteins lactoperoxidase, lysozyme, and lactoferrin in xerostomia: efficacy and safety. Orl Dis. 2002; 8(1):23-9.

2. Gibbons RJ, Hay DI. Human Salivary Acidic ProlineRich Proteins and Statherin Promote the attachment of Actinomyces viscosus LY7 to Apatitic Surfaces. Infect Immun. 1988; 56:439-45.

3. Laible NJ, Germaine GR. Bactericidal activity of human lysozyme, muramidase-inactive lysozyme, and cat- ionic polypeptides against Streptococcus sanguis and Streptococcus faecalis: inhibition by chitin oligosaccharides. Infect Immun. 1985 Jun; 48(3):720-8.

4. Wang YB, Germaine GR. Effect of lysozyme on glucose fermentation, cytoplasmic $\mathrm{pH}$, and intracellular potassium concentrations in Streptococcus mutans 10449. Infect Immun. 1991; 59(2):638-44.

5. Jenzano JW, Hogan SL, Lundblad RL. Factors Influencing Measurement of Human Salivary Lysozyme in Lysoplate and Turbidimetric Assays. J Clin Microbial. 1986; 24(6):963-7.

6. Aas JA, Paster BJ, Stokes LN, Olsen I, Dewhirst FE. Defining the normal bacterial flora of the oral cavity. J Clin Microbiol. 2005; 43:12.

7. Fujita A, Shimizu I, Abe T. Distribution of lysozyme and protease, and amino acid concentration in the guts of a wood-feeding termite. Reticulitermes spates (Kolbe): Possible digestion of symbiont bacteria transferred by trophallaxis. Physiological Entomology. 2001; 26:116-23.

8. Hultmark D. Insect lysozyme. In: Jolles P, editor. Lysozymes: Model Enzymes in Biochemistry and Biology. Birkhauser Vela Basel, Switzerland. 1996; 87-102.

9. Moto T. Engineering of lysozyme. In: Jolles P, editor. Lysozymes: Model Enzymes in Biochemistry and Biology. Birkhauser Vela, Basel, Switzerland. 1996; 163-81.

10. Jelles P, Jolles J. What's new in lysozyme research? Always a model system, today as yesterday. Molecular and Cellular Biochemistry. 1984; 63:165-89.

11. Kang D, Romans P, Lee JY. Analysis of a lysozyme gene from the malaria vector mosquito Anopheles gambiae. Gene. 1996; 174:239-44.

12. Barrett AJ. The Cystatins: A New Class of Peptidase Inhibitors. Trends Biochem Sci. 1987; 12:193-6. 